\title{
THE OPINION OF THERAPISTS AND SPECIALIZED DOCTORS ON THE PROVISION OF MEDICAL ASSISTANCE OF PATIENTS WITH TYPE 2 DIABETES IN POLYCLINICS IN ALMATY
}

\author{
AYGUL TAZHIYEVA ${ }^{1 *}$, VITALY REZNIK ${ }^{2}$, ZHAN ABYLAYULY ${ }^{3}$, GULZHANAT KUTTYKOZHAYEVA ${ }^{4}$
}

${ }^{1}$ Department of Epidemiology, Evidence-Based Medicine and Biostatistics, Kazakhstan Medical University “KSPH”, Almaty, Kazakhstan. ${ }^{2}$ Department of Biomedical Statistics and Evidence-Based Medicine, Al-Farabi Kazakh National University, Almaty, Kazakhstan. ${ }^{3}$ Department of Endocrinology, Asfendiyarov Kazakh National Medical University, Almaty, Kazakhstan. ${ }^{4}$ Department of Science and Innovation, Asfendiyarov Kazakh National Medical University, Almaty, Kazakhstan. Email: luna_1120@mail.ru

Received: 16 February 2019, Revised and Accepted: 13 March 2019

\section{ABSTRACT}

Objective: The objective of this research was to study the opinion of therapists and highly specialized doctors (cardiologist, neuropathologist, and oculist) in Almaty polyclinics on the provision of endocrinological care for patients with type 2 diabetes.

Methods: The sociological study was conducted on the basis of a specially developed questionnaire. The questionnaire consisted of 23 questions. The database was created in the Microsoft Access 2010 program. Statistical processing of data was carried out using the SPSS 22.0 software package. The average relative values have been calculated with the value of their standard error.

Results: Most patients with type 2 diabetes mellitus are observed in primary health care by therapists and endocrinologists. According to $86.7 \%$ of therapists, the number of patients with diabetes exceeds the number of registered patients and the determination of blood glucose level in the daily practice of therapists will reveal a large part of them. Most of the interviewed doctors believe that they have difficulties in servicing patients due to the presence of concomitant disease in patients, low adherence of patients, and a narrow choice of drugs for treatment. According to the opinion of doctors of different specialties (endocrinologists, cardiologists, neurologists, and oculists), when examining patients with type 2 diabetes, complications from the cardiovascular system, nervous system, and organ of vision are identified.

Conclusion: The organization of outpatient care for patients with type 2 diabetes mellitus should be interrelated by therapists and cardiologists, neurologists, and ophthalmologists. It should be based on continuity and interdisciplinary approach and is aimed to ensure patient satisfaction with the quality of care and adherence to treatment and to improve the quality of life.

Keywords: Primary care, Type 2 diabetes, General practitioners, Specialists.

(c) 2019 The Authors. Published by Innovare Academic Sciences PvtLtd. This is an open access article under the CC BY license (http://creativecommons. org/licenses/by/4. 0/) DOI: http://dx.doi.org/10.22159/ijap.2019.v11s3.M2022

\section{INTRODUCTION}

Today, there are about 451 million people with diabetes in the world, and by 2045 , the number of people with this disease will increase to 693 million, while the national cost of diabetes per year is 850 billion US dollars [1]. Annually, 4 million people die from diabetes due to cardiovascular disease [2], and the costs of treating a diabetic patient increases by $60-90 \%$ as the vascular problems progress [3]. According to the National Health Service (NHS), the UK spends $£ 9.8$ billion annually (up to $80 \%$ of costs) for treating complications of diabetes [4]. The Berlin Declaration notes that "The policy currently implemented in relation to diabetes and its complications are not sufficient to solve this problem at its root" and stresses the need to maintain and strengthen health at the primary level in the context of primary health care, as described in the Alma-Ata Declaration. The Berlin Declaration acts as a global call for action by all countries on diabetes and identifies four main strategies that are measurable and internationally applicable: Disease prevention, early detection, timely monitoring, and access to appropriate health services.

The above mentioned four directions cover the whole range of primary health care, as described in the Alma-Ata Declaration [5-7]. Maintaining adequate glycemic control in patients with diabetes is necessary to prevent micro- and macrovascular complications and premature death [8]. In connection with the ever-increasing number of people with diabetes and the lack of endocrinologists, [9] in the context of primary health care, general practitioners carry out diabetes management while endocrinologists manage just $20 \%$ of the patients. [10]. Family doctors play a significant role in the treatment of patients with diabetes, in changing their lifestyle and preventing complications $[11,12]$.
Diabetes management is, especially, difficult in primary health care due to the need for significant resources and the necessary knowledge of specialists. Questionnaires were completed by 362 family physicians (79\% response rate). And as surveyed by family doctors, only $9 \%$ refer their patients with diabetes to secondary care [13]. The American Association for the Study of Diabetes in 2018 published standards for the provision of medical care for diabetes, based on evidence-based recommendations aimed at managing risks, in particular, cardiovascular diseases, including hypertension, integration of new technologies in diabetes management, and screening in a group increased risk [14]. The review [15] found that multicomponent professional interventions (e.g., audit and feedback, decision-making by consensus and peer review, central computerized tracking systems, and nurses who regularly contacted patients) can improve the effectiveness of the provided medical services to patients with diabetes.

\section{MATERIALS AND METHODS}

Materials

The sociological study was conducted on the basis of a specially developed questionnaire. The questionnaire consisted of 23 questions. The database was created in the Microsoft Access 2010 program. Statistical processing of data was carried out using the SPSS 22.0 software package. The average relative values have been calculated with the value of their standard error.

\section{RESULTS AND DISCUSSION}

A survey of doctors was conducted in almost all polyclinics in Almaty. The number of specialists in polyclinics varied. There could 
be two specialists or no doctors at all. 105 doctors who agreed to be interviewed included 30 therapists, 22 cardiologists, 25 neurologists, and 28 oculists. When determining the sample size, a possible error might have occurred, not exceeding 5\%. Respondents are informed about the purpose of the study and are aware of its anonymous and voluntary nature.

A total of 30 therapists took part in the survey, $90.0 \%$ of whom were women and $10.0 \%$ were men. According to the age distribution, the respondents aged 40-49 represented the largest proportion (43.3\%). Among the surveyed therapists, the number of specialists with $2-5$ years of professional service prevailed (56.7\%). Therapists with the highest qualification grade made up $40.0 \%$, those without a qualification grade approached to $26.7 \%$, the number of specialists with the first qualification grade was equal to $23.3 \%$, and those with the second qualification grade constituted $10.0 \%$ of total as mentioned in Table 1.

Table 1: Personal details of the respondents

\begin{tabular}{|c|c|c|}
\hline Characteristics & $\begin{array}{l}\text { Absolute } \\
\text { number }\end{array}$ & $\%$ к "Total," $\overline{\bar{X}} \pm \varsigma \bar{x}^{a}$ \\
\hline \multicolumn{3}{|l|}{ Gender } \\
\hline Male & 3 & $10.0 \pm 5.48$ \\
\hline Female & 27 & $90.0 \pm 5.48$ \\
\hline Total & 30 & $100.0 \pm 0.0$ \\
\hline \multicolumn{3}{|l|}{ Age } \\
\hline Under the age of 30 & 2 & $6.67 \pm 4.55$ \\
\hline 30-39 years old & 6 & $20.0 \pm 7.30$ \\
\hline 40-49 years old & 13 & $43.3 \pm 9.05$ \\
\hline 50-59 years old & 9 & $30.0 \pm 8.37$ \\
\hline 60-69 years old & - & - \\
\hline Over the age of 70 & - & - \\
\hline Total & 30 & $100.0 \pm 0.0$ \\
\hline \multicolumn{3}{|l|}{$\begin{array}{l}\text { Length of service in the } \\
\text { profession }\end{array}$} \\
\hline Under 1 year & 2 & $6.67 \pm 4.55$ \\
\hline From 2 to 5 years & 17 & $56.7 \pm 9.05$ \\
\hline Over 5 years & 9 & $30.0 \pm 8.37$ \\
\hline Over 10 years & 2 & $6.67 \pm 4.55$ \\
\hline Total & 30 & $100.0 \pm 0.0$ \\
\hline \multicolumn{3}{|l|}{$\begin{array}{l}\text { Possession of qualification } \\
\text { grades by the specialists }\end{array}$} \\
\hline I qualification grade & 7 & $23.3 \pm 7.72$ \\
\hline II qualification grade & 3 & $10.0 \pm 5.48$ \\
\hline The highest qualification grade & 12 & $40.0 \pm 8.94$ \\
\hline No qualification grade & 8 & $26.7 \pm 8.07$ \\
\hline Total & 30 & $100.0 \pm 0.0$ \\
\hline
\end{tabular}

${ }^{a}$ Mean \pm SD

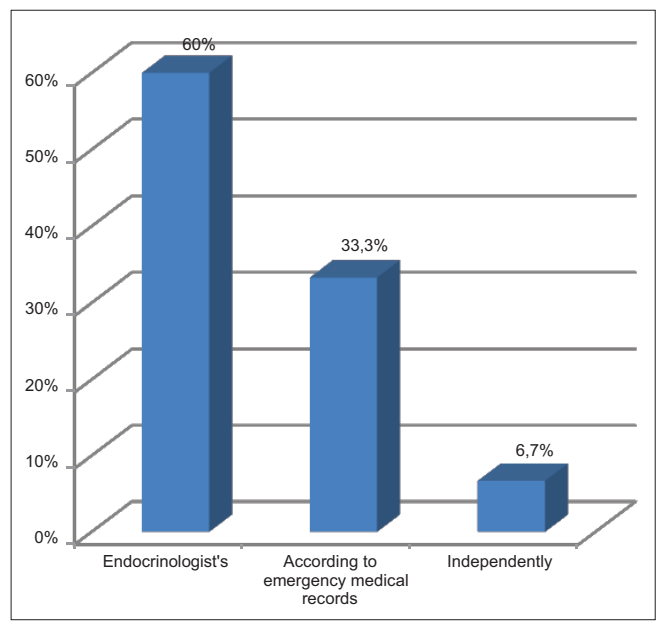

Fig. 1: Encounter of patients with type 2 diabetes to the therapists by the referral from other specialists
In most cases, patients with type 2 diabetes come to the therapists by the referral from the endocrinologist constitute $60.0 \%$, the percentage of patients by the records of emergency medical care is amounted to $33.3 \%$, and those who come independently comprise 6.7\% (Fig. 1).

As $86.7 \%$ of therapists think on the question of the need to determine the level of blood glucose in the routine practice of therapists, it will be possible to identify the majority of cases of type 2 diabetes at an early stage, whereas $13.3 \%$ of specialists responded negatively (Fig. 2). $100 \%$ of the respondents responded negative to the question: "Is there a glucose meter in the office?".

In the view of $53.3 \%$ of therapists, the use of screening scales and questionnaires will allow to timely detect complications of type 2 diabetes. At the same time, $26.7 \%$ of therapists believe that timely preventive examinations (eye and leg examinations) will make it possible to identify these complications in a timely manner, and only $13.3 \%$ of therapists presume that the introduction of an interdisciplinary approach will help in identifying complications of diabetes mellitus and the number of some other methods used for this purpose is amounted to $6.7 \%$ (Fig. 3 ).

According to the opinion of $33.3 \%$ of therapists, when advising patients with type 2 diabetes, difficulties arise due to the presence of concomitant disease, $30.0 \%$ of therapists consider low adherence of

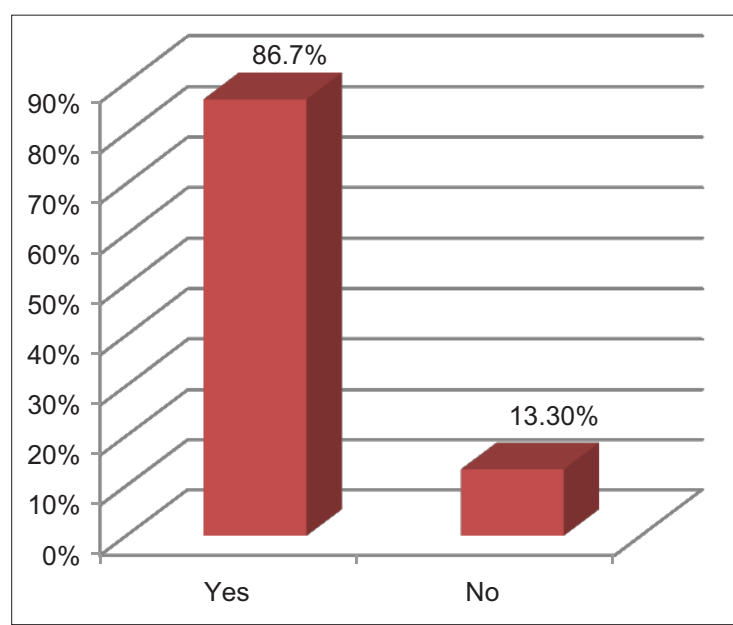

Fig. 2: The opinion of therapists on the determination of blood glucose level in routine practice

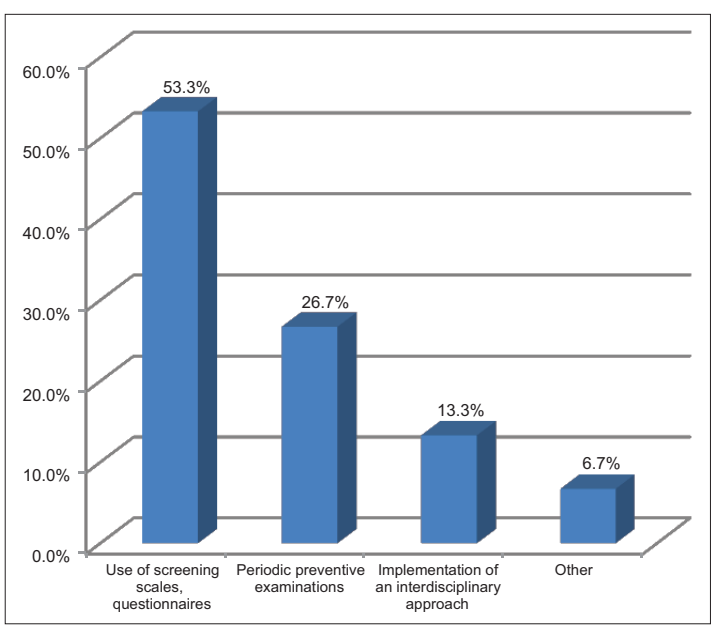

Fig. 3: The opinion of therapists on the measures to identify complications of type 2 diabetes 
Table 2: Personal details of the respondents

\begin{tabular}{|c|c|c|}
\hline Characteristics & $\begin{array}{l}\text { The absolute } \\
\text { number }\end{array}$ & $\%$ к “Total," $\overline{\bar{X}}_{ \pm \varsigma \overline{\mathrm{x}}^{\mathrm{a}}}$ \\
\hline \multicolumn{3}{|l|}{ Gender } \\
\hline Male & 3 & $13.6 \pm 7.32$ \\
\hline Female & 19 & $86.4 \pm 7.32$ \\
\hline Total & 22 & $100.0 \pm 0.0$ \\
\hline \multicolumn{3}{|l|}{ Age } \\
\hline Under the age of 30 & - & - \\
\hline $30-39$ years old & 5 & $22.7 \pm 8.93$ \\
\hline $40-49$ years old & 10 & $45.5 \pm 10.6$ \\
\hline $50-59$ years old & 7 & $31.8 \pm 9.93$ \\
\hline 60-69 years old & - & - \\
\hline Over the age of 70 & - & - \\
\hline Total & 22 & $100.0 \pm 0.0$ \\
\hline \multicolumn{3}{|l|}{$\begin{array}{l}\text { Length of service in the } \\
\text { profession }\end{array}$} \\
\hline Under 1 year & - & - \\
\hline From 2 to 5 years & 5 & $22.7 \pm 8.93$ \\
\hline Over 5 years & 8 & $36.4 \pm 10.3$ \\
\hline Over 10 years & 9 & $40.9 \pm 10.5$ \\
\hline Total & 22 & $100.0 \pm 0.0$ \\
\hline \multicolumn{3}{|l|}{$\begin{array}{l}\text { Possession of qualification } \\
\text { grades by the specialists }\end{array}$} \\
\hline I qualification grade & 2 & $9.09 \pm 6.13$ \\
\hline II qualification grade & 3 & $13.6 \pm 7.32$ \\
\hline $\begin{array}{l}\text { The highest qualification } \\
\text { grade }\end{array}$ & 10 & $45.5 \pm 10.6$ \\
\hline No qualification grade & 7 & $31.8 \pm 9.93$ \\
\hline Total & 22 & $100.0 \pm 0.0$ \\
\hline
\end{tabular}

${ }^{\mathrm{a} M e a n} \pm \mathrm{SD}$

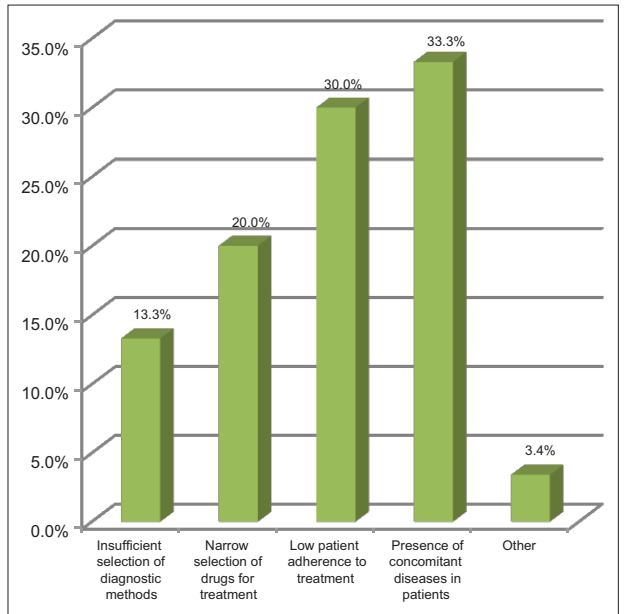

Fig. 4: The opinion of therapists on counseling patients with type 2 diabetes

patients, $20.0 \%$ of therapists believe that it is due to a narrow choice of medications, $13.3 \%$ of therapists consider an insufficient choice of diagnostic methods, and $3.3 \%$ of therapists noted other difficulties (Fig. 4).

\section{Cardiologist}

A total of 22 cardiologists participated in the survey, $86.4 \%$ of whom were female and $13.6 \%$ male. Among cardiologists, specialists aged 40-49 years were predominant, accounting for $45.5 \%$. $40.9 \%$ of cardiologists had a work experience of $>10$ years. The number of doctors with the highest category made up $45.5 \%$, while $31.8 \%$ had no qualification category as shown in Table 2 .

Patients with type 2 diabetes do not periodically undergo examination by cardiologists, which leads to the development of complications in

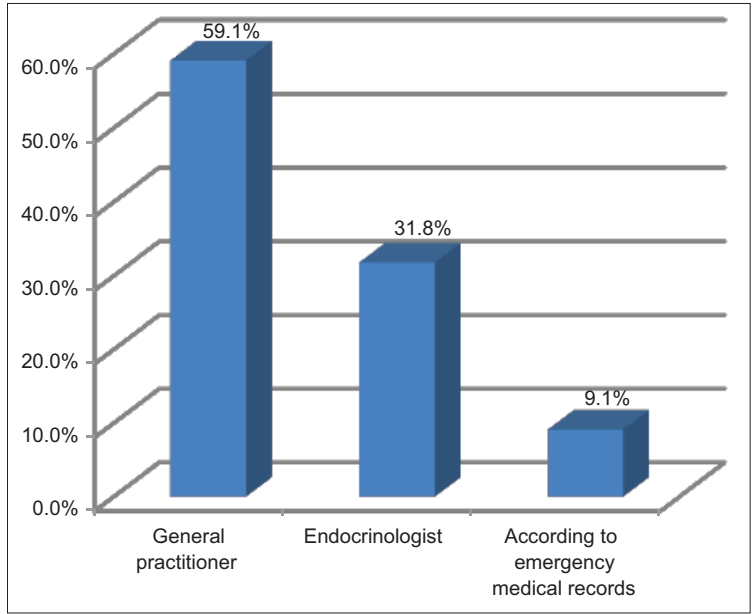

Fig. 5: Encounter of patients with type 2 diabetes to the cardiologists by the referral from other specialists

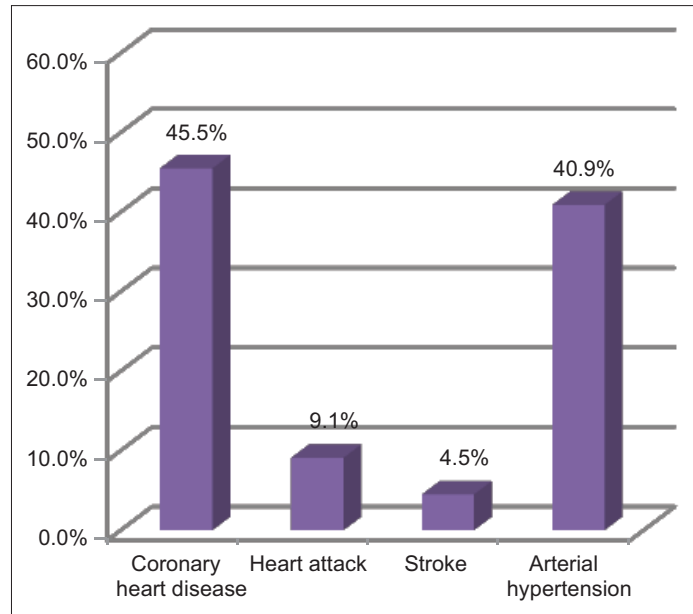

Fig. 6: Complications of the cardiovascular system in patients with type 2 diabetes

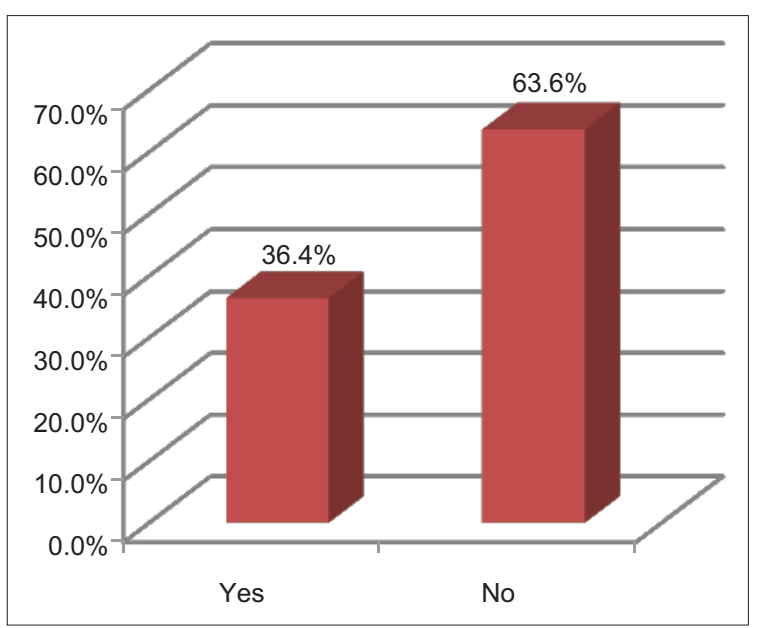

Fig. 7: Information on the level of glycosylated hemoglobin and fasting glycemia

the cardiovascular system. The interaction and continuity in the work of doctors of different specialties in the care of patients with type 2 diabetes will reduce the incidence of complications in these patients. The results of the survey showed that $59.1 \%$ of patients apply to a 
Table 3: Personal details of the respondents

\begin{tabular}{lll}
\hline Characteristics & $\begin{array}{l}\text { The absolute } \\
\text { number }\end{array}$ & \% к “Total," $\overline{\bar{X}} \pm \varsigma \overline{\mathrm{X}}^{\mathrm{a}}$ \\
\hline Gender & 7 & \\
Male & 18 & $28.0 \pm 8.98$ \\
Female & 25 & $72.0 \pm 8.98$ \\
Total & & $100.0 \pm 0.0$ \\
Age & - & - \\
Under the age of 30 & 6 & $24.0 \pm 8.54$ \\
30-39 years old & 7 & $28.0 \pm 8.98$ \\
40-49 years old & 12 & $48.0 \pm 9.99$ \\
50-59 years old & - & - \\
60-69 years old & - & $100.0 \pm 0.0$ \\
Over the age of 70 & 25 & - \\
Total & - & $16.0 \pm 7.33$ \\
Length of service in the profession & $36.0 \pm 9.60$ \\
Under 1 year & 4 & $48.0 \pm 9.99$ \\
From 2 to 5 years & 9 & $100.0 \pm 0.0$ \\
Over 5 years & 12 & \\
Over 10 years & 25 & $24.0 \pm 8.54$ \\
Total & & \\
Possession of qualification & & \\
grades by the specialists & & \\
I qualification grade & 5 & $64.0 \pm 9.93$ \\
Il qualification grade & 6 & \\
The highest qualification & 11 & \\
grade & & \\
No qualification grade & 3 & \\
Total & 25 & \\
\hline
\end{tabular}

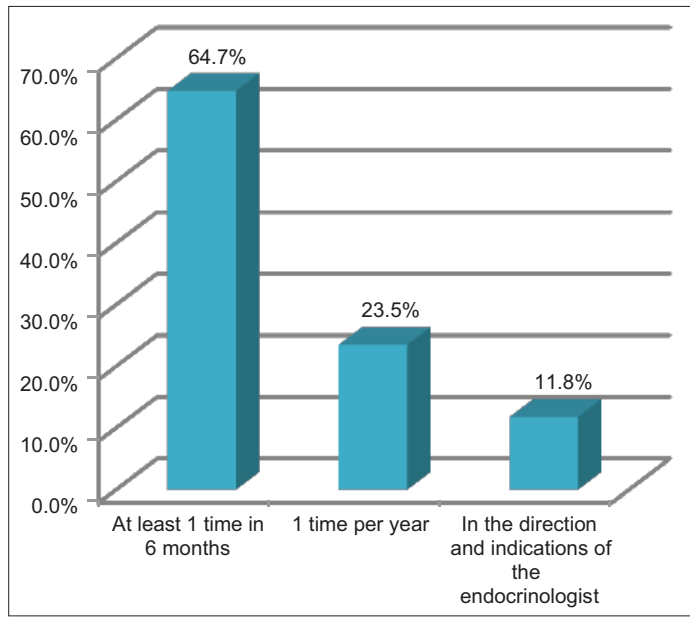

Fig. 8: Patients' referral frequency to a cardiologist

cardiologist at the direction of general practitioners, $31.8 \%$ of patients visit cardiologists according to the direction of an endocrinologist, and $9.1 \%$ of patients refer to a cardiologist only from emergency medical records (Fig. 5).

It should be noted that all cardiologists identified that there are complications from the cardiovascular system in the treatment of patients with type 2 diabetes. In the opinion of $45.5 \%$ of cardiologists, coronary heart disease is most often detected in patients, and the cases with arterial hypertension are amounted to $40.9 \%$. At the same time, $9.1 \%$ of the respondents noted myocardial infarction and $4.5 \%$ had a stroke (Fig. 6)

About $63.6 \%$ of cardiologists believe that when the patient was treated, information about the level of glycosylated hemoglobin (HbA1c) and fasting glycemia was absent. However, in the opinion of $36.4 \%$ of

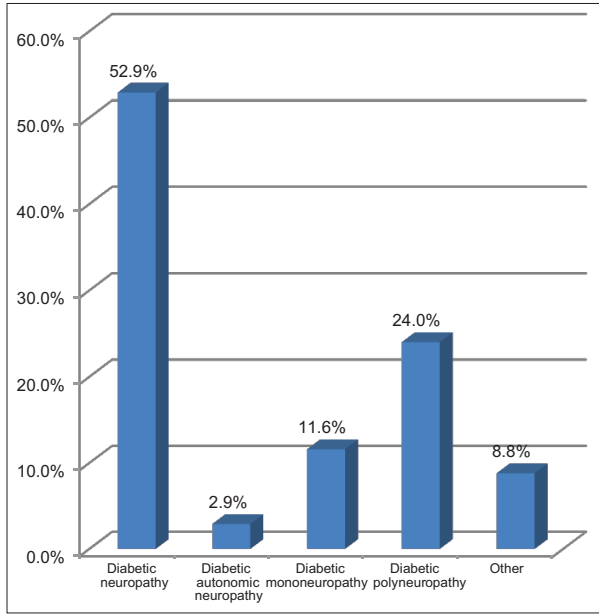

Fig. 9: Complications of type 2 diabetes at the time of a neurologists' examination

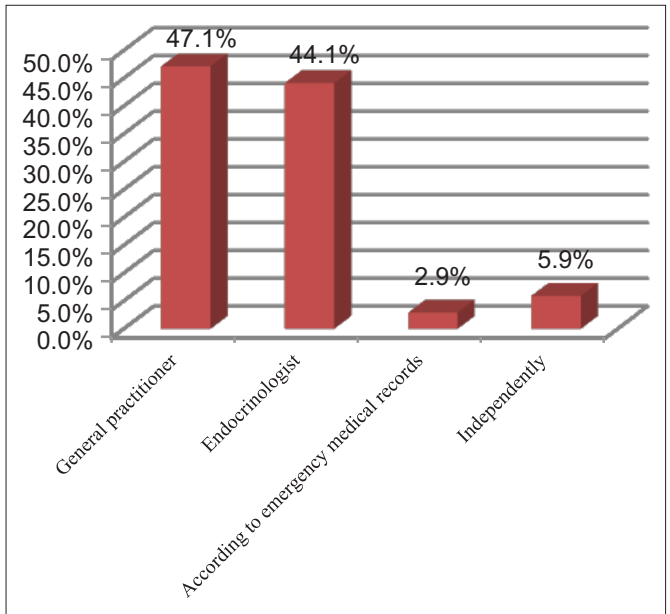

Fig. 10: Encounter of patients with type 2 diabetes to the neurologists by the referral from other specialists

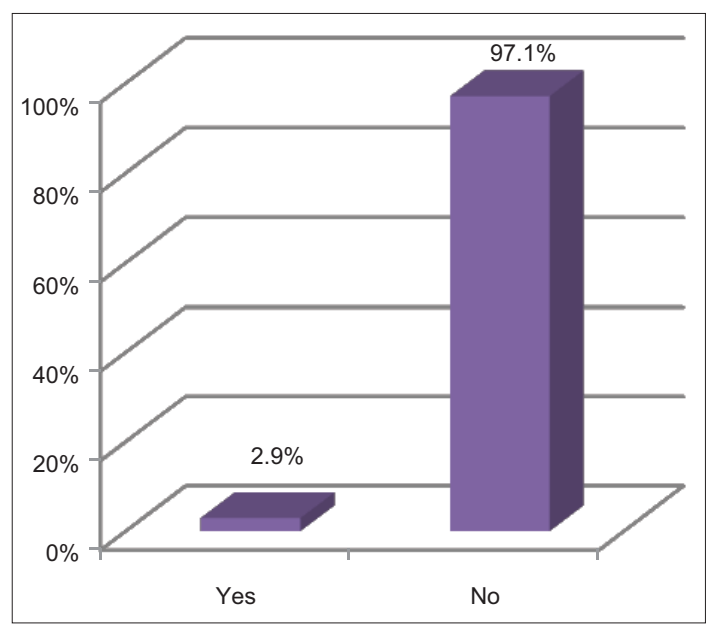

Fig. 11: Registration of patients with complications of type 2 diabetes by neurologists

cardiologists, there was information on the level of HbA1c and fasting glycemia in the patient (Fig. 7).

About $64.7 \%$ of respondents think that patients with type 2 diabetes mellitus should visit cardiologists' office at least once every 6 months, 


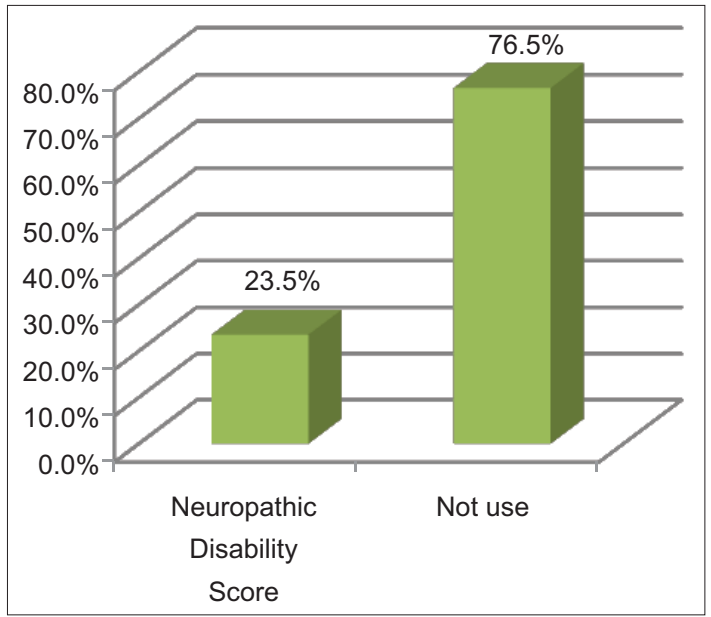

Fig. 12: Application of integrated scales to assess clinical symptoms of complications of type 2 diabetes

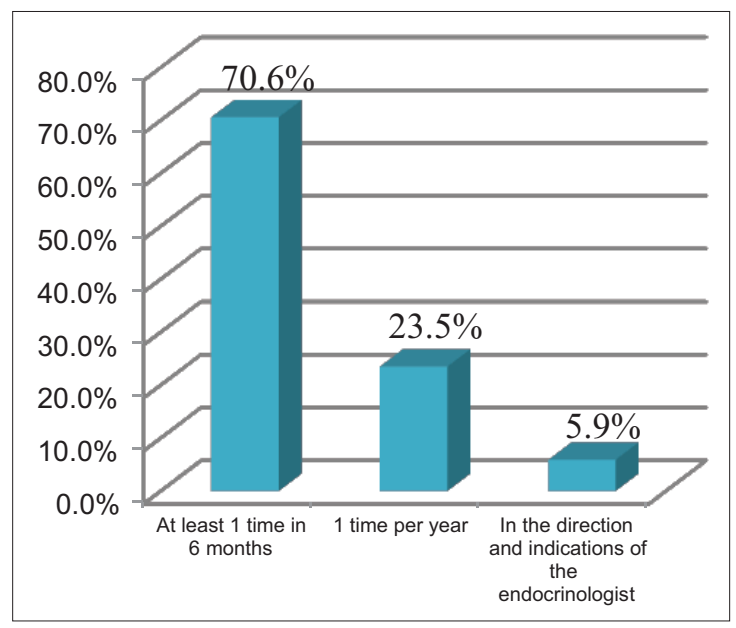

Fig. 13: Application of integrated scales to assess clinical symptoms of complications of type 2 diabetes

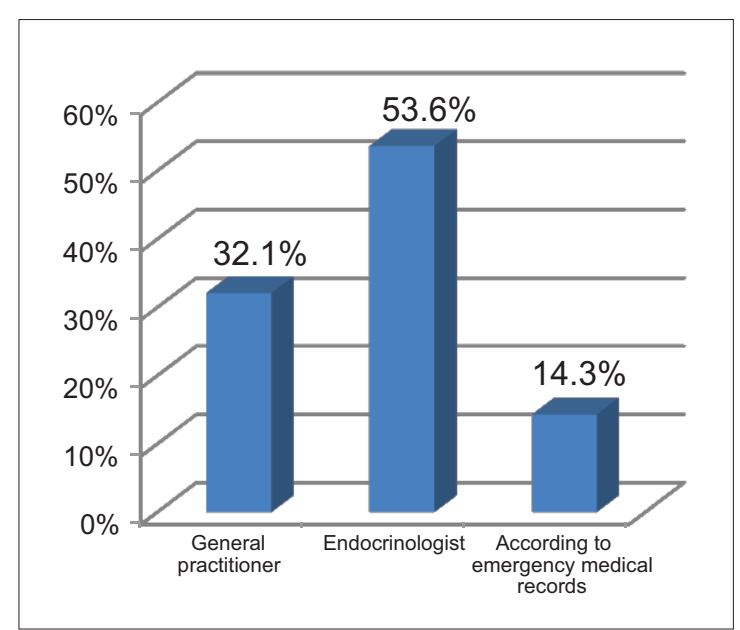

Fig. 14: Encounter of patients with type 2 diabetes to the oculists by the referral from other specialists

whereas $23.5 \%$ of cardiologists believe that once a year is enough for them. In this case, according to $11.8 \%$ of cardiologists, it is necessary to visit cardiologists by the referral from and indications of the endocrinologist (Fig. 8).

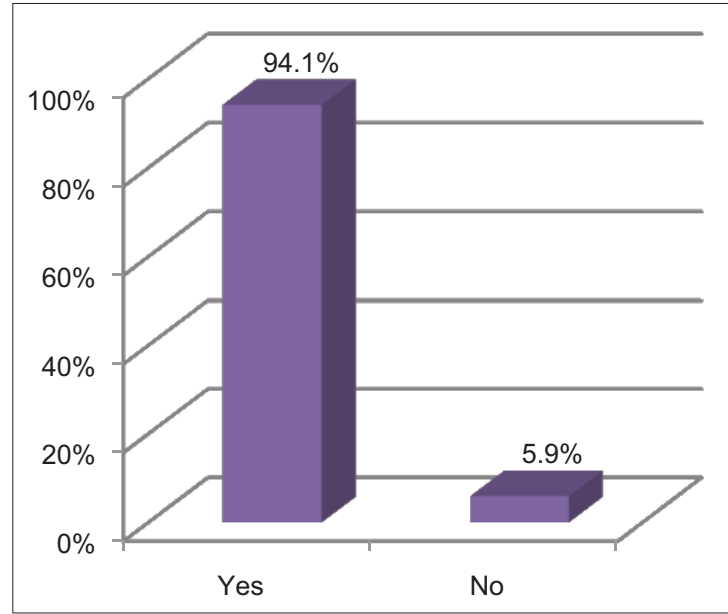

Fig. 15: The opinion of vision specialists on counseling the complications of the eyes in patients with type 2 diabetes

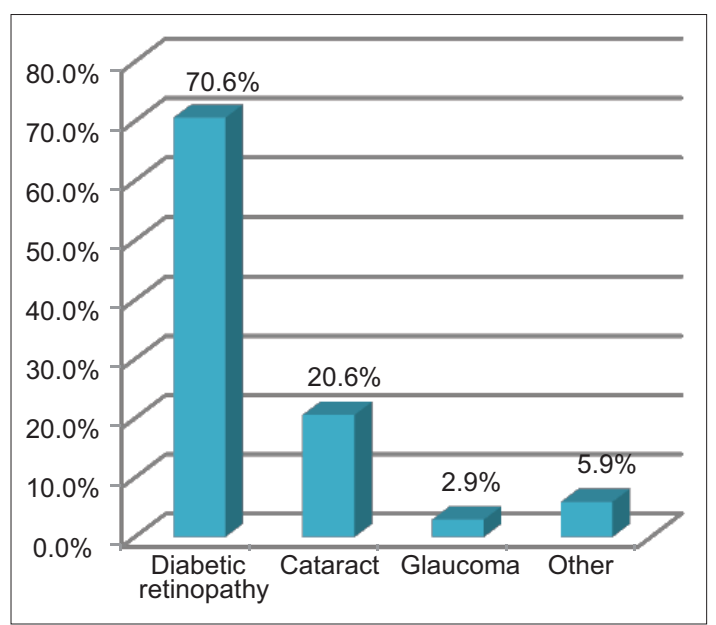

Fig. 16: Complications of type 2 diabetes at the time of an oculists' examination

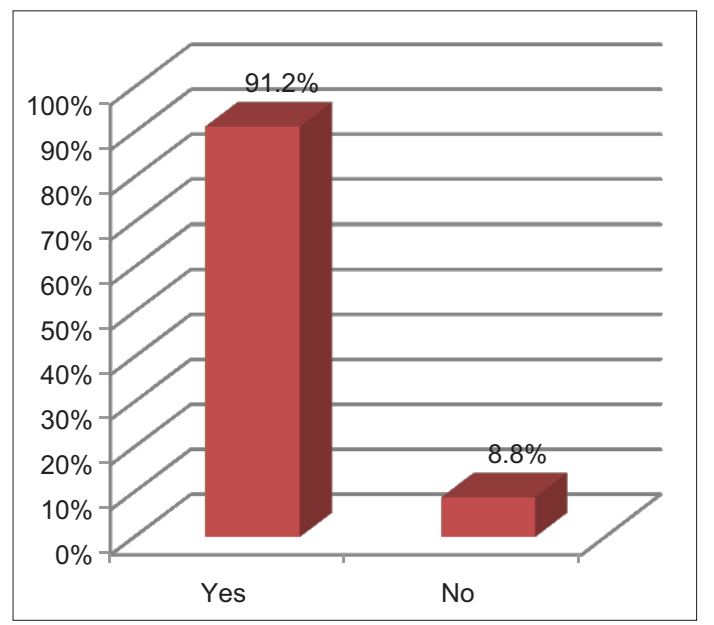

Fig. 17: Registration of patients with complications of type 2 diabetes by vision specialists

\section{Neurologists}

In total, 25 neuropathologists took part in the survey, $79.4 \%$ of them were females and $20.6 \%$ of males. By the age groups, the largest proportion $(38.2 \%)$ constituted neurologists aged $40-49$ years. The percentage of neuropathologists with $>10$ years of work experience 
Table 4: Personal details of the respondents

\begin{tabular}{|c|c|c|}
\hline Characteristics & $\begin{array}{l}\text { The absolute } \\
\text { number }\end{array}$ & $\%$ к “Total," $\overline{\bar{X}} \pm \varsigma \bar{x}^{a}$ \\
\hline \multicolumn{3}{|l|}{ Gender } \\
\hline Male & 5 & $17.9 \pm 7.24$ \\
\hline Female & 23 & $82.1 \pm 7.24$ \\
\hline Total & 28 & $100.0 \pm 0.0$ \\
\hline \multicolumn{3}{|l|}{ Age } \\
\hline Under 1 year & - & - \\
\hline From 2 to 5 years & 9 & $32.1 \pm 8.83$ \\
\hline Over 5 years & 13 & $46.4 \pm 9.42$ \\
\hline Over 10 years & 6 & $21.4 \pm 7.75$ \\
\hline Total & - & - \\
\hline Under 1 year & - & - \\
\hline From 2 to 5 years & 28 & $100.0 \pm 0.0$ \\
\hline \multicolumn{3}{|l|}{$\begin{array}{l}\text { Length of service in the } \\
\text { profession }\end{array}$} \\
\hline Under 1 year & - & - \\
\hline From 2 to 5 years & 8 & $28.6 \pm 8.54$ \\
\hline Over 5 years & 13 & $46.4 \pm 9.42$ \\
\hline Over 10 years & 7 & $25.0 \pm 8.18$ \\
\hline Total & 28 & $100.0 \pm 0.0$ \\
\hline \multicolumn{3}{|l|}{$\begin{array}{l}\text { Possession of qualification } \\
\text { grades by the specialists }\end{array}$} \\
\hline I qualification grade & 4 & $14.3 \pm 6.61$ \\
\hline II qualification grade & 7 & $25.0 \pm 8.18$ \\
\hline $\begin{array}{l}\text { The highest qualification } \\
\text { grade }\end{array}$ & 9 & $32.1 \pm 8.83$ \\
\hline No qualification grade & 8 & $28.6 \pm 8.54$ \\
\hline I qualification grade & 28 & $100.0 \pm 0.0$ \\
\hline
\end{tabular}

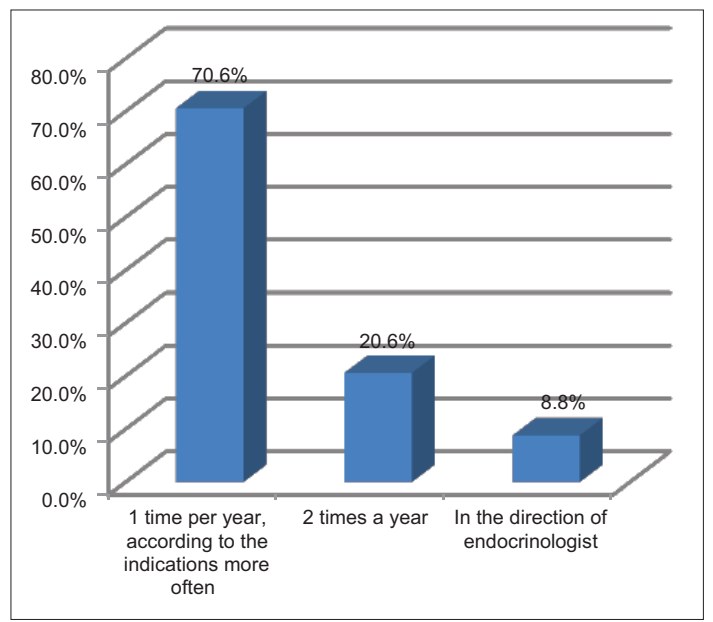

Fig. 18: Patients' referral frequency to a vision specialist

prevailed and reached $61.8 \%$. Doctors with the highest category made up $55.9 \%$, those with the second qualification grade comprised $17.6 \%$, and the number of neurologists possessing the first qualification grade reached $5.9 \%$ as shown in Table 3.

As shown by the results of the survey, at the time of the examination, neuropathologist determined $52.9 \%$ of cases with diabetic neuropathy, $23.5 \%$ of cases with diabetic polyneuropathy, and $11.8 \%$ of cases with diabetic mononeuropathy (Fig. 9).

Nearly $47.1 \%$ of the respondents indicated that the patients with type 2 diabetes come to see a neurologist by the referral from the therapist or GP, while $44.1 \%$ noted that they were referred from the endocrinologist (Fig. 10).

About $97.1 \%$ of the surveyed neurologists answered negatively to the question "Do you keep records of patients with complications of type 2 diabetes?" (Fig. 11).
The majority of $76.5 \%$ of neurologists do not apply complex scales to assess the clinical symptoms of complications of type 2 diabetes in their practice, while $23.5 \%$ of neurologists use the neuropathy disability score scale (Fig. 12).

About $70.6 \%$ of the interviewed respondents believe that patients should visit the neuropathologists at least once every 6 months. However, $23.5 \%$ of neurologists assume that only once a year should be enough for them, whereas $5.9 \%$ of neuropathologists claim that there is a need to refer to the direction from and indications of the endocrinologist (Fig. 13).

\section{Vision specialists}

A total of 28 oculists were participated in the survey. Among them, the number of women was $82.4 \%$ and men $17.9 \%$. By age groups, the largest proportion was made up of specialists aged 40-49 years (46.4\%). Among vision specialists, the number of those with $>5$ years of work experience prevailed and accounted for $46.4 \%$. The number of doctors with the highest qualification grade was $32.1 \%$, the number of those who did not have the qualification grade was $28.6 \%$, with the respondents having the second qualification grade comprising $25.0 \%$, and the percentage of doctors who had the first qualification grade constituted $14.3 \%$ as mentioned in Table 4 .

As the results of the survey have shown, $53.6 \%$ of the respondents claim that patients come to see the oculist by the referral from the endocrinologist, $32.1 \%$ of patients turn to the oculists for the appointment of the GP, and only $14.3 \%$ of patients are enrolled in emergency medical records (Fig. 14).

Nearly $94.1 \%$ of the ophthalmologists claim that, when patients were treated, there were complications from the eyes, while 5.9\% of the respondents noted their absence (Fig. 15).

According to the survey, at the time of the examination, $70.6 \%$ of oculists in patients with type 2 diabetes revealed diabetic retinopathy, while $20.6 \%$ revealed cataracts, $2.9 \%$ revealed glaucoma, $5.9 \%$ - others. This provision indicates the development of eye complications in patients with type 2 diabetes (Fig. 16).

About $91.2 \%$ of the surveyed ophthalmologists record patients with diabetic retinopathy, while $8.8 \%$ of the respondents gave a negative response (Fig. 17).

According to $70.6 \%$ of ophthalmologists, patients with type 2 diabetes should visit the ophthalmologists once a year, and if there are some medical reasons, they should see a doctor more often. Moreover, $20.6 \%$ of the surveyed ophthalmologists believe that it is necessary to be examined by a doctor 2 times a year. Furthermore, $8.8 \%$ of the interviewed specialists think that patients see the oculists by the referral from the endocrinologists (Fig. 18).

\section{CONCLUSION}

Therefore, as the results of the study have shown, the doctors of different specialties have difficulties in counseling patients with type 2 diabetes and this situation might be due to the presence of existing complications in patients and insufficient knowledge of specialists. The situation is complicated by the fact that, in some clinics, there are no necessary specialists. To improve the level of care, patients should be referred to refresher courses for physicians and doctors of various specialties (endocrinologists, cardiologists, neurologists, and oculists).

\section{CONFLICTS OF INTEREST}

All authors have none to declare.

\section{REFERENCES}

1. International Diabetes Federation. Atlas. $8^{\text {th }}$ ed. Brussels, Belgium: IDF Diabetes; 2017. Available from: http://www.diabetesatlas.org/ 
component/attachments/?task $=$ download\&id $=254$.

2. Alberti KG, Zimmet $\mathrm{P}$, Shaw J. International diabetes federation: A consensus on type 2 diabetes prevention. Diabet Med 2007;24:451-63.

3. Dancer S, Courtney M. Improving diabetes outcomes: Framing research into the chronic care model. J Am Acad Nurse Pract 2010;22:580-5.

4. Hex N, Bartlett C, Wright D, Taylor M, Varley D. Estimating the current and future costs of type 1 and type 2 diabetes in the UK, including direct health costs and indirect societal and productivity costs. Diabet Med 2012;29:855-62

5. The Berlin Declaration a Collective Ambition for Policy Change to Drive Early Action in Type 2 Diabetes; 2017. p. 12-24. Available from: http://www.idf.org.

6. Ceriello A, Gavin JR $3^{\text {rd }}$, Boulton AJM, Blickstead R, McGill M, Raz I, et al. The berlin declaration: A call to action to improve early actions related to type 2 diabetes. How can specialist care help? Diabetes Res Clin Pract 2018;139:392-9.

7. Kalra S, Lauritzen T, Sharmanov T, Akanov Z, Al Awadi F, Das AK, et al. Alma-ata to berlin: Diabetes prevention and treatment to achieve healthy living. Diabet Med 2017;34:1169-70.

8. Park SY, Jang EJ, Shin JY, Lee MY, Kim D, Lee EK, et al. Prevalence and predictors of hypoglycemia in South Korea. Am J Manag Care
2018;24:278-86

9. Vigersky RA, Fish L, Hogan P, Stewart A, Kutler S, Ladenson PW, et al. The clinical endocrinology workforce: Current status and future projections of supply and demand. J Clin Endocrinol Metab 2014;99:3112-21.

10. Saudek CD. The role of primary care professionals in managing diabetes. J Clin Diabetes 2002;20:65-6.

11. Hilts L, Howard M, Price D, Risdon C, Agarwal G, Childs A, et al. Helping primary care teams emerge through a quality improvement program. J Fam Pract 2013;30:204-11.

12. Bardach SH, Schoenberg NE. Primary care physicians' prevention counseling with patients with multiple morbidity. Qual Health Res 2012;22:1599-611

13. Fogelman Y, Goldfracht M, Karkabi K. Managing diabetes mellitus: A Survey of attitudes and practices among family physicians. J Community Health 2015;40:1002-7.

14. American Diabetes Association. Standards of medical care in diabetes-2018 abridged for primary care providers. Clin Diabetes 2018;36:14-37.

15. Renders CM, Valk GD, Griffin S, Wagner EH, Eijk JT, Assendelft WJ, et al. Interventions to improve the management of diabetes mellitus in primary care, outpatient and community settings. Cochrane Database Syst Rev 2001;1:CD001481. 